Al1102 765151

\section{RESEARCH SERIES}

NBSIR 883374.

Vharen 18, 1988
NBS

PUBLICATIONS

\section{A SCHEME FOR TRANSLATING CONTROL FLOW IN THE C PROGRAMMING L ANGUAGE TO GRAFCET WITH EXAMPLES}

By:

Bruce th. Thomas

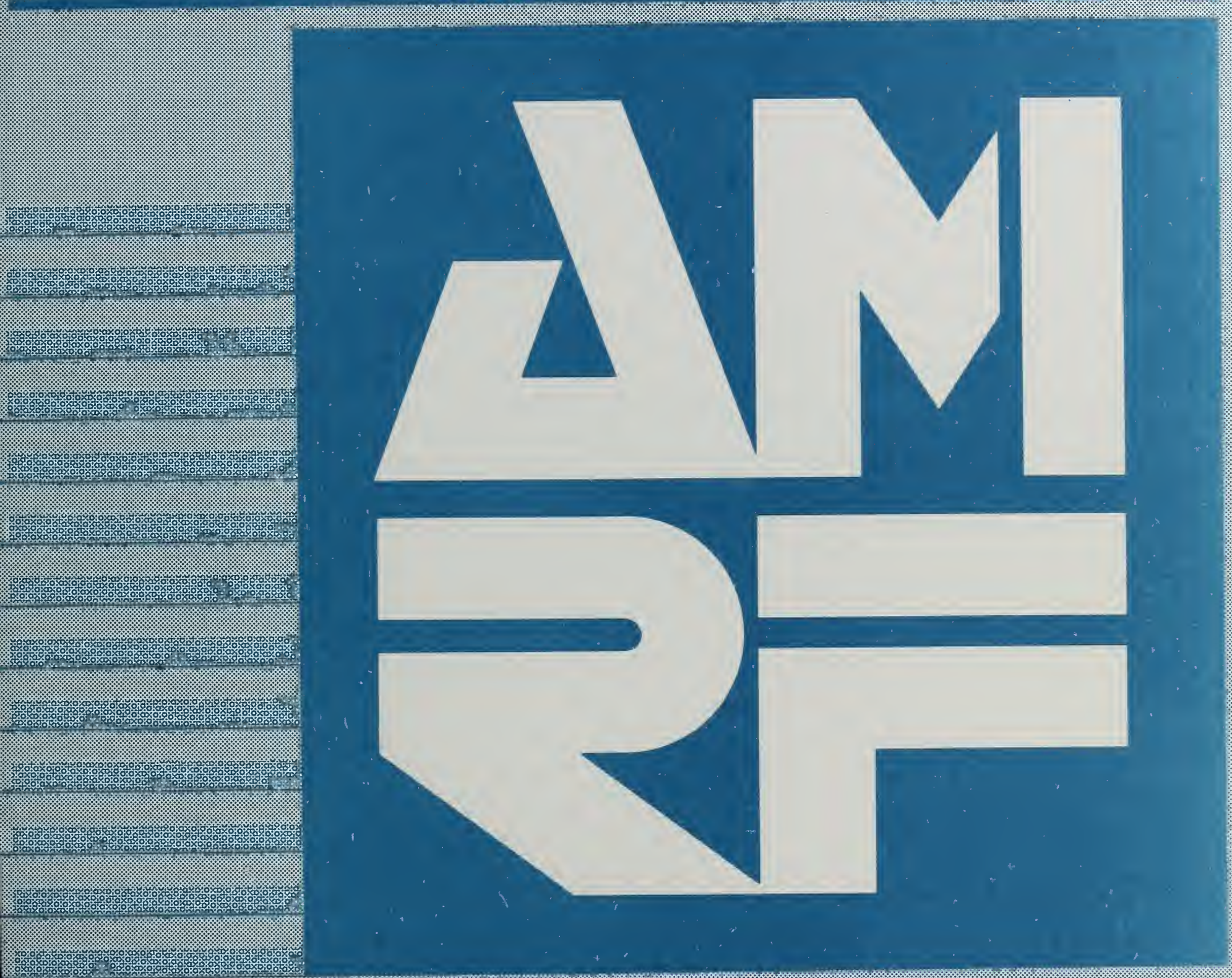

\begin{tabular}{|c|}
\hline$Q Q C$ \\
\hline 100 \\
\hline .456 \\
\hline$\# 88-3741$ \\
\hline 1988 \\
\hline$c .2$ \\
\hline
\end{tabular}





\title{
A Scheme for Translating Control Flow in the C Programming Language to Grafcet with Examples
}

\author{
Bruce Hunter Thomas
}

This publication was prepared by United States Government employees as part of their official duties and is, therefore, a work of the U. S. Government and not subject to copyright.

Certain commercial equipment, instruments, or materials are identified in this paper in order to adequately specify the experimental procedure. Such identification does not imply recommendation or endorsement by the National Bureau of Standards, nor does it imply that the materials or equipment identified are necessarily the best available for the purpose. 



\title{
A Scheme for Translating Control Flow in the $\mathrm{C}$ Programming Language to Grafcet with Examples
}

\author{
Bruce Hunter Thomas
}

\section{National Bureau of Standards}

\author{
Gaithersburg, MD
}

Keywords: Grafcet, $\mathrm{C}$ programming language, control flow, programming languages

\begin{abstract}
:
The purpose of this paper is to show a translation scheme from control flow in the C programming language to the Grafcet language. Grafcet is a graphical language for expressing control flow. Grafcet is used to design parallel systems such as in a manufacturing environment. The control constructs covered in this paper are: conditional statement, while, do, for, switch, break, continue, goto, label, and null. The Grafcet used in this paper is the language, as augmented by Savoir. The $\mathrm{C}$ programming language is the one described by Kernighan and Ritchie. This translation is to be used as a reference for programmers to translate existing $\mathrm{C}$ source code into Grafcet.
\end{abstract}

\section{Introduction:}

Grafcet is a powerful graphical language for expressing control flow. Savoir has implemented a version of Grafcet which uses $C$ source code[1]. Grafcet is an excellent tool for designing, documenting, and demonstrating the control flow of a system. A system which is already written in $\mathrm{C}$ can be translated into a set of Grafcet programs. This paper shows a translation scheme from the control flow in a $\mathrm{C}$ program to a set of Grafcet programs. The $\mathrm{C}$ source code constructs are those defined by Kernighan and Ritchie [2].

A basic introduction to the portion of the Grafcet language needed for the translations is given in the paper. A number of the extensions to Grafcet by Savoir, used for translating, are described. The translation of these $\mathrm{C}$ source code control constructs are described: conditional statement, while, do, for, switch, break, continue, goto, label, and null.

The problem of representing data flow or a definitive method for translating functions into a Grafcet form from a $\mathrm{C}$ program is not directly addressed, but a discussion of the problems of representing $\mathrm{C}$ functions in Grafcet is given. A possible scheme for functions translated to macro steps is outlined, but a definitive solution is not given.

\section{Background:}

For the purposes of this paper we will define our problem as translating a set of $\mathrm{C}$ source code control constructs into a Grafcet system, where a Grafcet system is a hierarchy of Grafcet programs. A Grafcet program is either a main program or a macro program. There is 
only one main program for each Grafcet system and it is at the top of the hierarchy. A macro program is an expanded Grafcet program from a macro step. Below is a definition of the Grafcet primitives, the goal of using these primitives, and the features Savoir augmented to the Grafcet language.

The Grafcet language has three major primitives: regular steps, macro steps, and transitions. Regular steps allow the user to represent an arbitrary control action in the form of embedded C source code. The Grafcet places a dot in the regular step's square to indicate that $C$ source code is embedded in it, see the example below. Macro steps allow the user to name embedded Grafcet macro programs as control actions. Transitions act as gates on the flow of control through the Grafcet program. Associated with each transition is a C expression which determines if control can pass through this point. If the expression evaluates to False, the gate stops the control flow. If the expression is True, the gate allows the control flow to continue. These primitives can be connected to form a control flow path by attaching a link between two primitives. A link can only be attached between a step primitive and a transition primitive; that is to say a transition primitive cannot be linked to another transition primitive. These links are represented by a line from one primitive to another, sometimes an arrowhead is used to indicate the direction of the control flow. Examples of what these primitives look like are shown below. In these examples $\mathbf{0}$ and M1 are labels supplied by the Grafcet programming environment, and label is a user supplied name for a step.

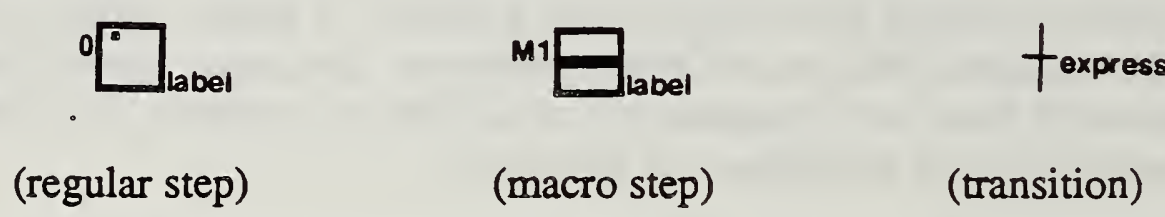

It has been shown that all the other $\mathrm{C}$ control constructs can be formed from just conditional and goto statements [3],[4]. Therefore by translating the $C$ conditional and goto statements first, the rest of the $\mathrm{C}$ control constructs will follow.

There are three features with which Savoir has augmented the Grafcet language that are used in translating $\mathrm{C}$ source code into Grafcet. The Grafcet transitions use $\mathrm{C}$ expressions for the condition that determines whether or not control can pass through the transition. In an asynchronous branch a special transition condition of otherwise was added. An asynchronous branch is a single step followed by two or more transitions. Control can flow through one or more of the transitions whose conditions are true. Otherwise is defined as a condition that is true if the conditions of the transitions to its left in a set of asynchronous branches are false. An example of an asynchronous branch with an otherwise transition is shown below. 
Example of an asynchronous branch with an otherwise transition:

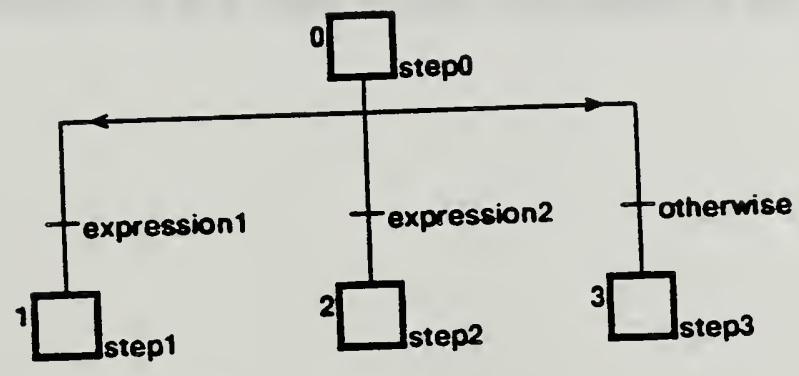

(asynchronous branch)

The $\mathrm{C}$ programming language was chosen for this translation because Savoir has augmented Grafcet to support $\mathrm{C}$ source code in their "regular step." This translation can be extended to other languages with similar constructs such as Pascal, Fortran, or Algol 60.

\section{Definitions:}

In the examples of Grafcet programs, $\mathrm{T}$ is defined as True or:

$$
\mathrm{T} !=0
$$




\section{Description of Translation:}

The translation of these $\mathrm{C}$ source code control constructs is described in this section: null, label, goto, conditional statement, while, do, for, switch, break, and continue. To help clarify the descriptions of translations a mixture of flowcharts, C statements, or examples are used. The translated Grafcet statements are fragments which may be linked together to form a complete Grafcet program.

Null statement: ;

A null statement translates to a regular step with no $\mathrm{C}$ source code associated with it. (For the examples shown here, the null statement regular steps will be labeled null.)

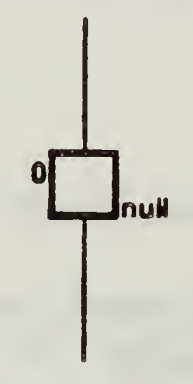

(null in Grafcet)

Labeled statement: identifier :

The label statement in $C$ is used for a destination location for the goto statement. There is no explicit translation into Grafcet, but the goto statement is translated. 
Goto statement: goto identifier ;

As described above, control follows the links in a Grafcet program. Each link acts similar to a goto from point to point in a Grafcet program. A link must be contained in one Grafcet macro program. The goto statement is not the most popular construct in the $\mathrm{C}$ language; therefore it is anticipated the $C$ goto construct will not be used often [5].

Example goto statement :

statement1;

if expression goto NEXT;

statement2;

NEXT: statement3;

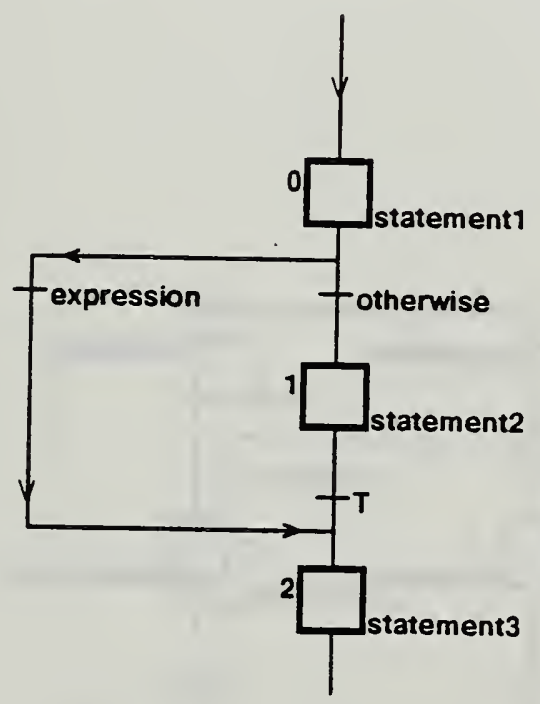

(goto in Grafcet) 
Conditional statement: if ( expression) statement

if ( expression ) statementl else statement 2

The conditional statement is made with two asynchronous branches. One branch is a transition with the condition expression, and the other transition has the condition otherwise.

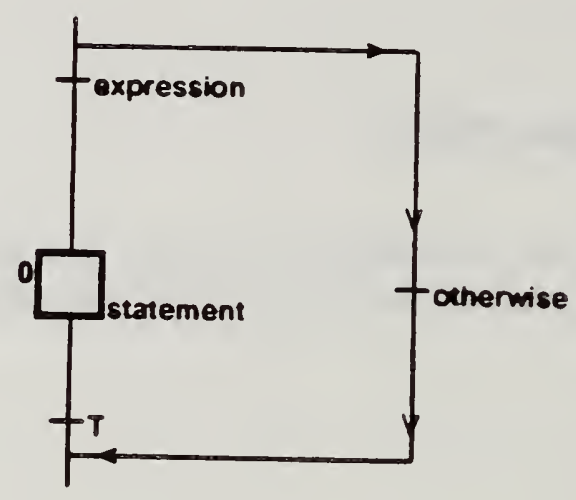

(if then in Grafcet)

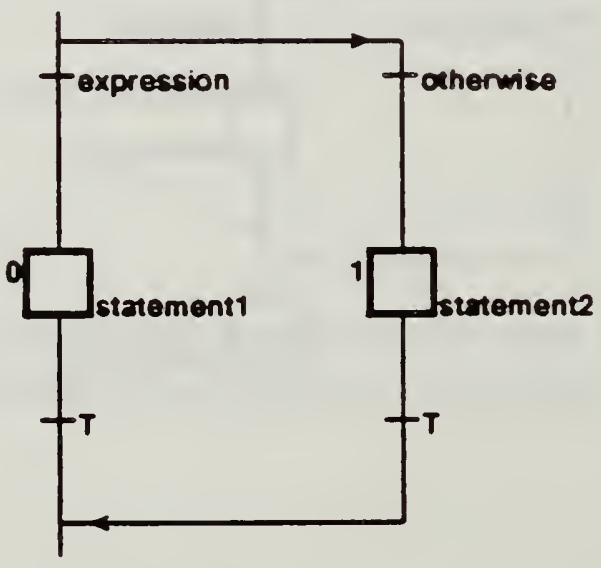

(if then else in Grafcet) 
While statement: while ( expression ) statement

The logic for the while statement is as follows [6]:

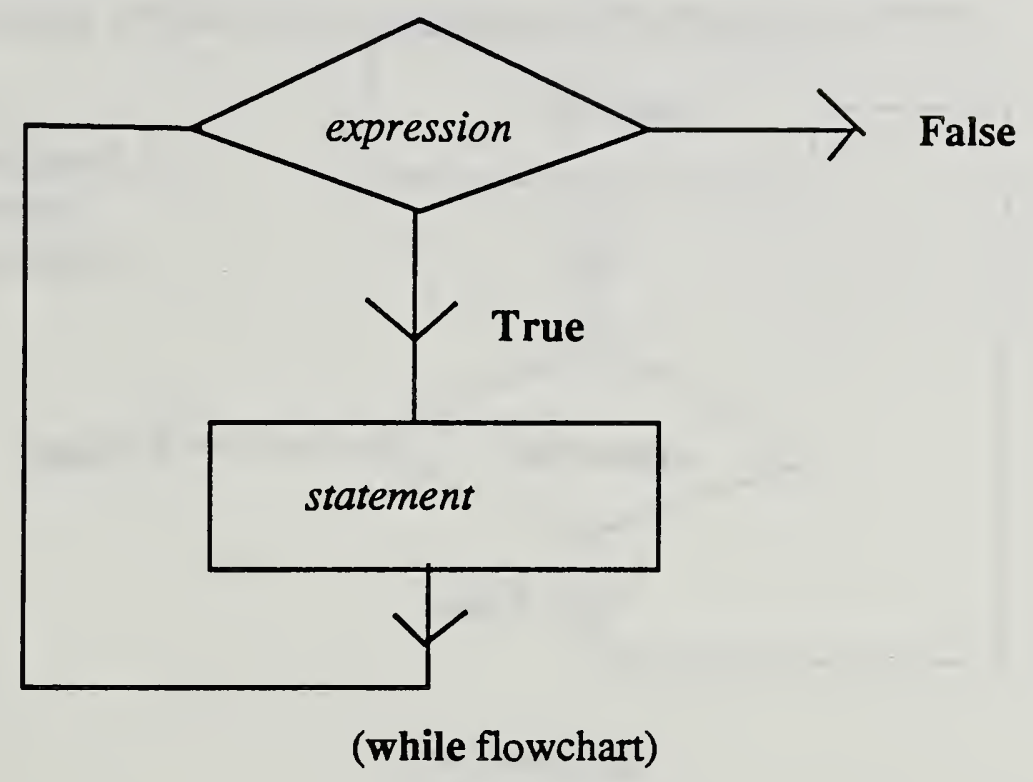

The Grafcet equivalent is:

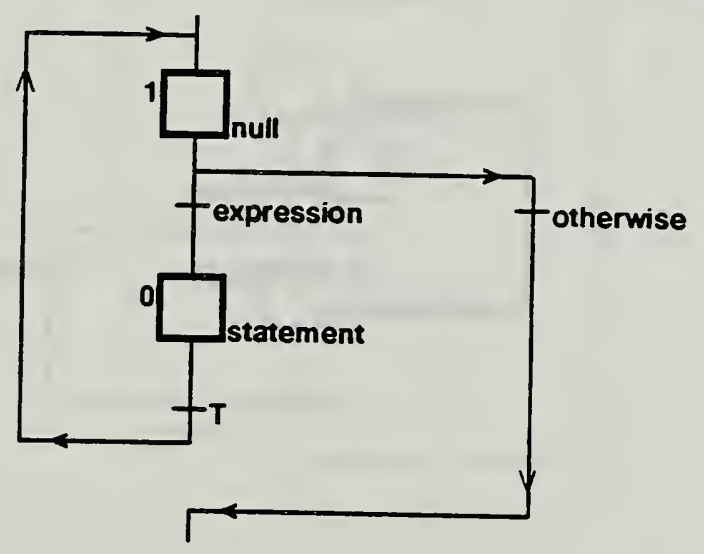

(while in Grafcet) 
Do statement : do statement while (expression) ;

The logic for the do statement is as follows:

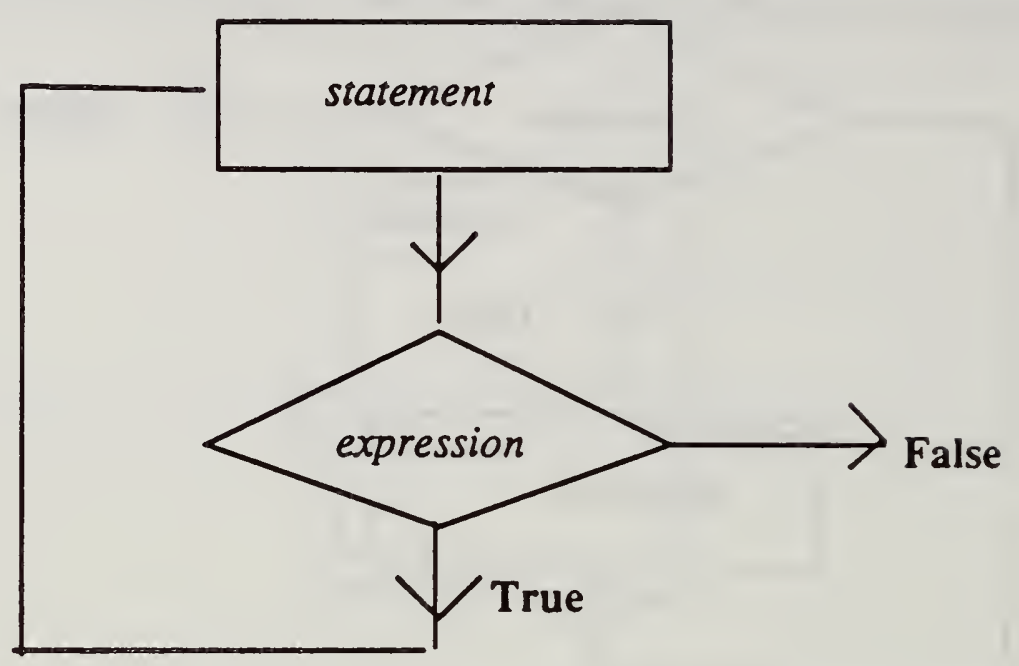

(do flowchart)

The Grafcet equivalent is:

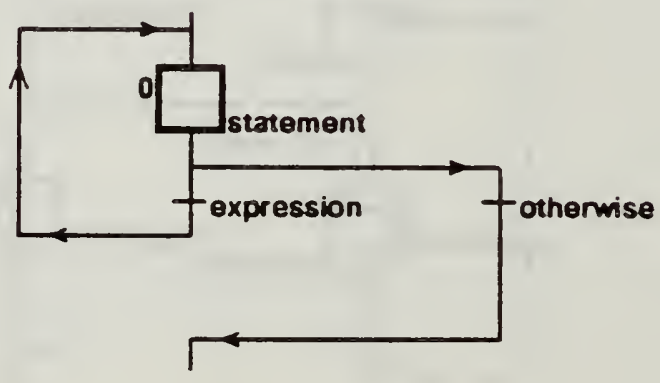

I

(do in Grafcet) 
For statement : for ( expression1 ; expression2 ; expression3 ) statement

The for statement can be expressed as a while statement; where expressionl and expression 3 are constructed by placing $C$ source code of the expressions in regular steps. The $\mathrm{C}$ source code using a while loop to represent a for statement is shown:
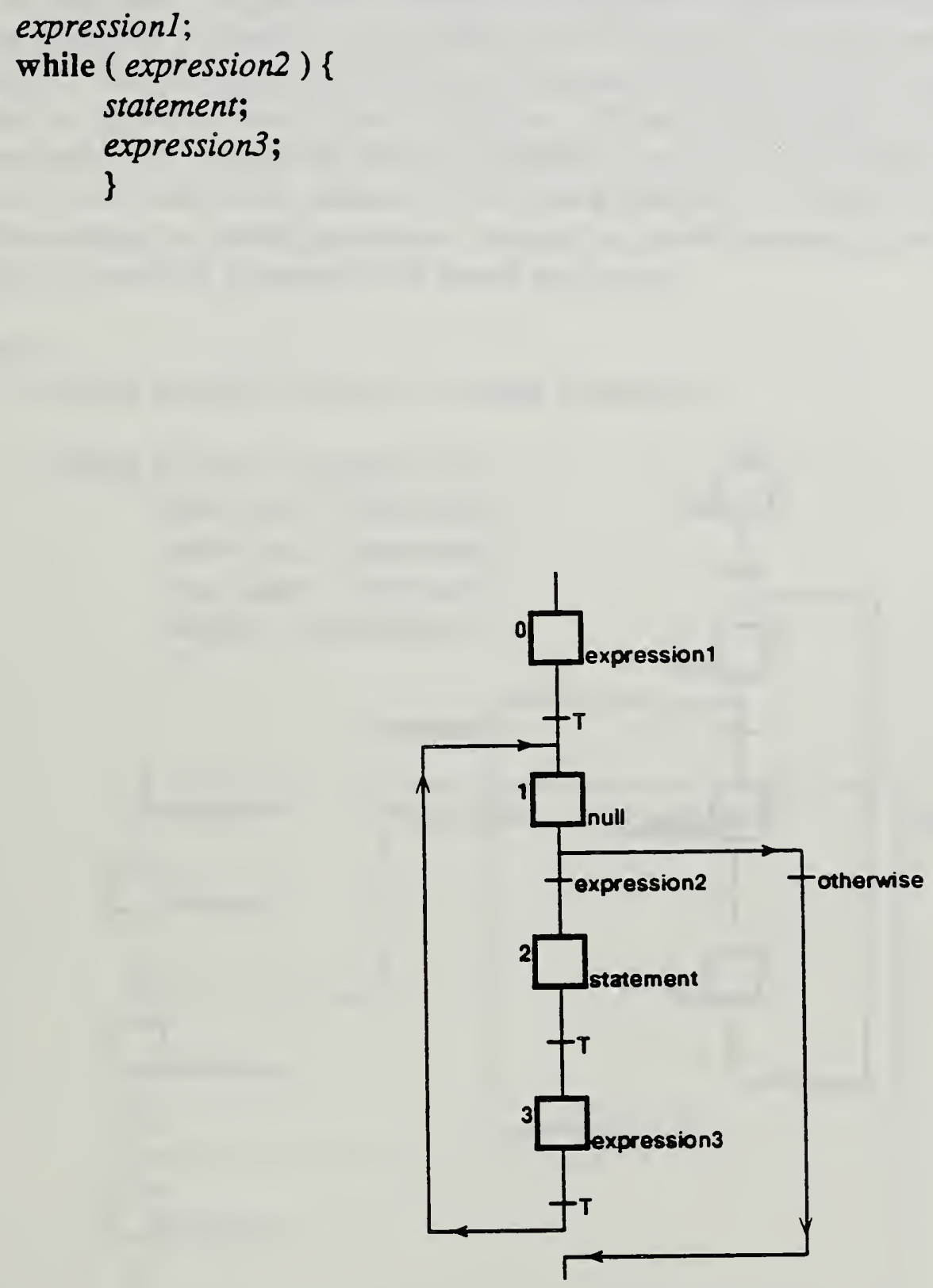

(for in Grafcet) 
Each of the three expressions in the for statement are optional. If the expressions expression1 or expression 3 are not used in a for statement, the unused expression is replaced by a null statement in the Grafcet program. If the expression expression 2 is not used in a for statement, the expression in transition replaced by $\mathrm{T}$ in the Grafcet program. The Grafcet for loop shown below demonstrates all of the replacements of the three optional expressions, even though the Grafcet code functional makes little sense.

for (;;) statement

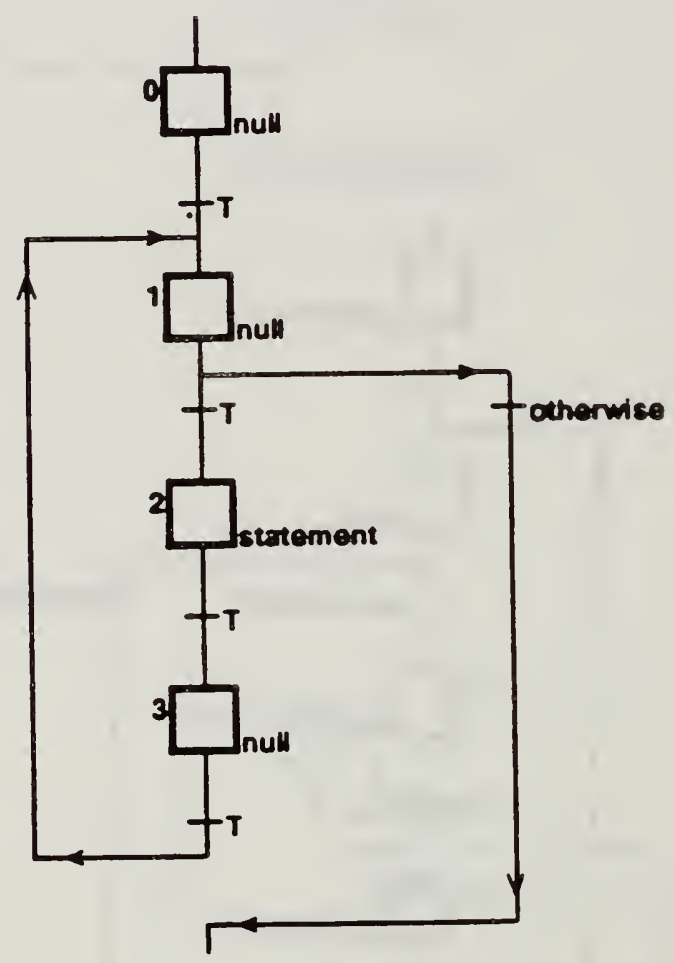

(for (;;) in Grafcet) 
Switch statement : switch (expression) statement

case constant-expression :

default :

The switch statement can easily be expressed with only conditional and goto statements [3]. The case label is replaced by an equivalence comparison between the constantexpression and the expression. The default case is handled by the otherwise condition in the Grafcet. The translation of the switch statement in Grafcet always produces a default statement to allow the control flow to continue. If there is no default in the $C$ source code, a null statement must be inserted after the otherwise condition. The switch statement is commonly used with break statements, the break statement is defined in the next section. The first example is a switch statement without the break statements, and the second example is the switch statement with break statements.

Examples :

The switch statement without the break statements:
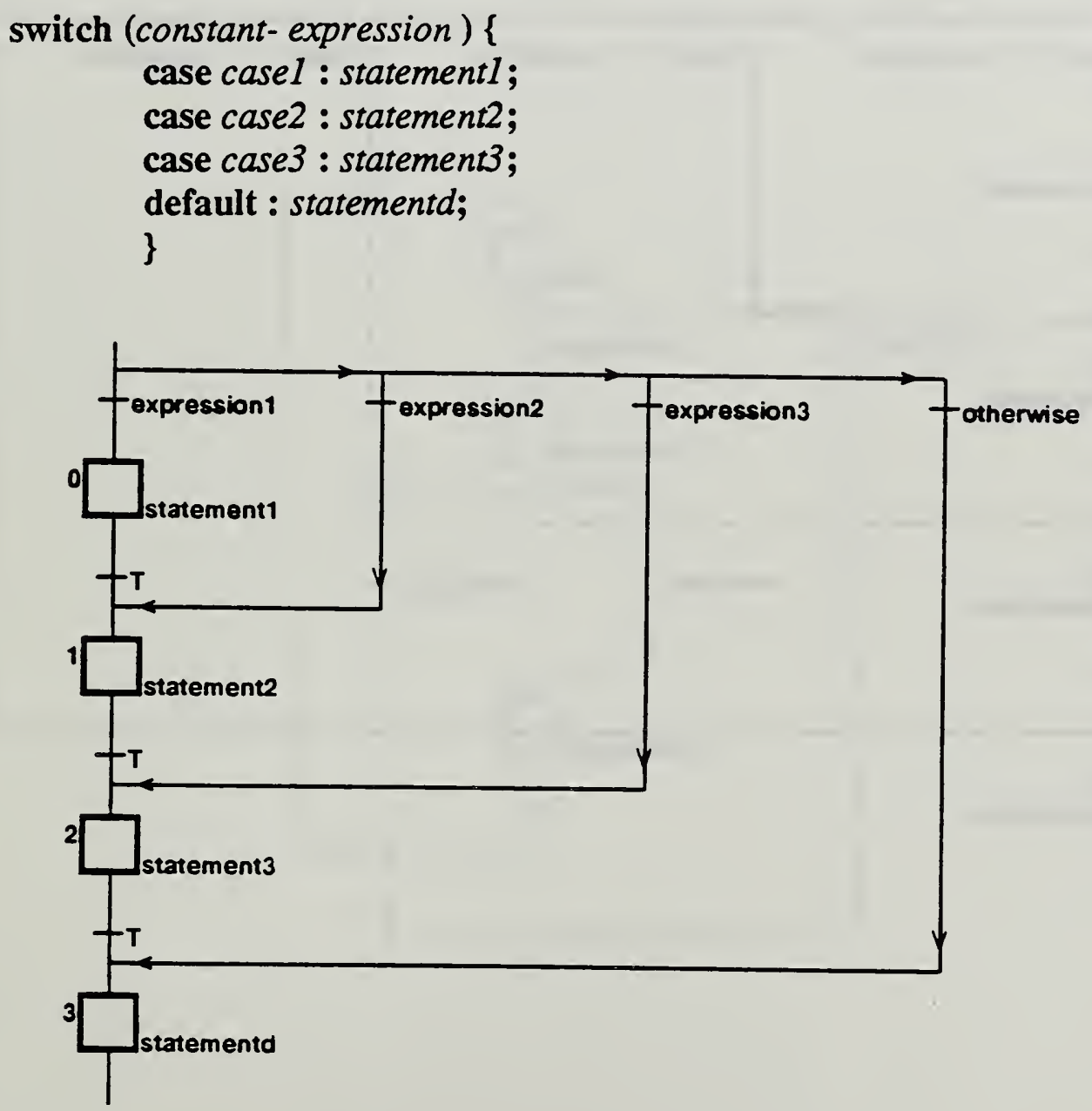

(switch in Grafcet) 
The switch statement with the break statements:

$$
\begin{gathered}
\text { switch (expression ) }\{ \\
\text { case case } 1: \text { statement } 1 ; \\
\text { break; } \\
\text { case case } 2: \text { statement2; } \\
\text { break; } \\
\text { case case3 : } \begin{array}{c}
\text { statement3; } \\
\text { break; }
\end{array} \\
\text { default : statementd; } \\
\}
\end{gathered}
$$

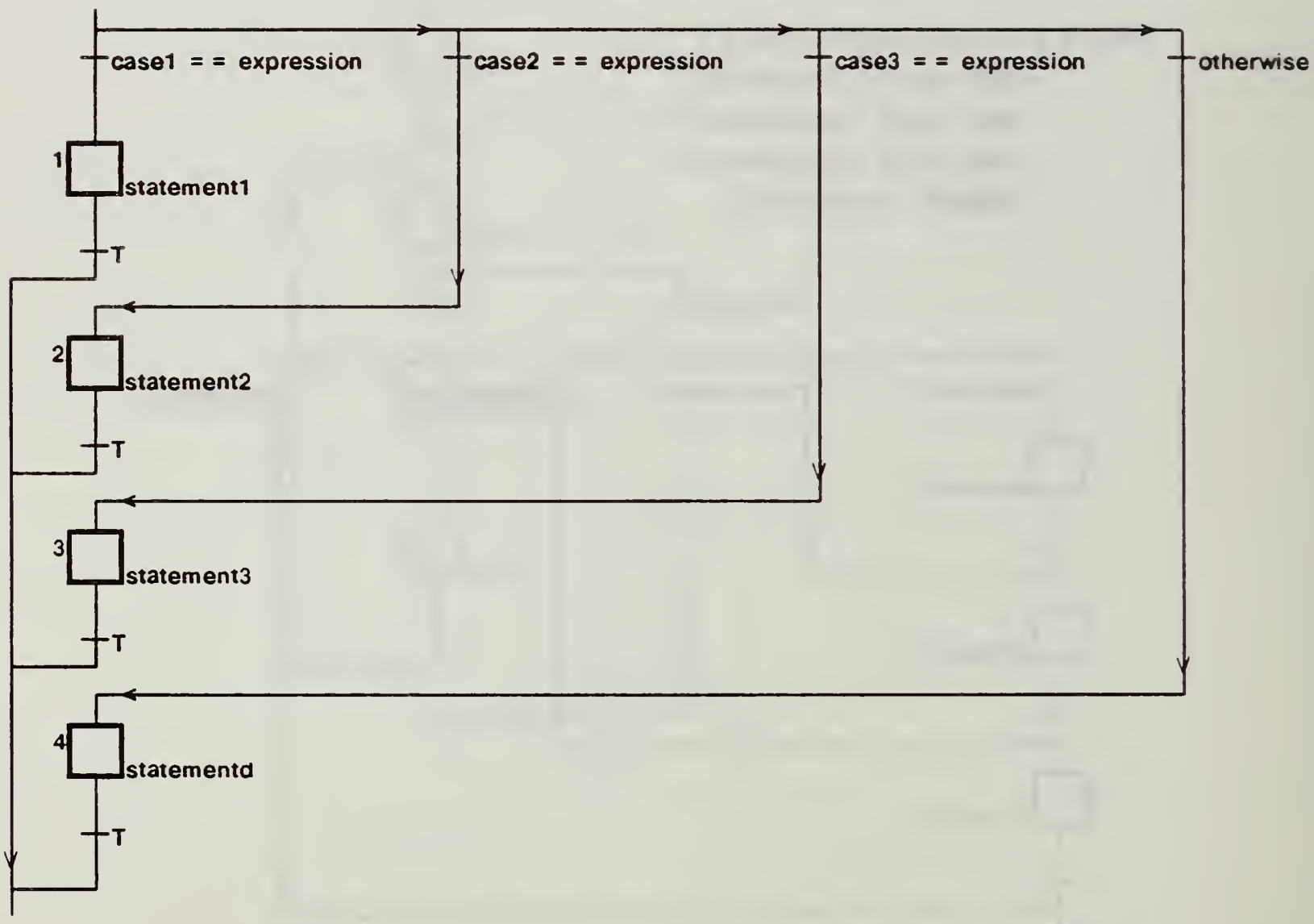

(case in Grafcet) 
The last two constructs, break and continue, can be expressed in the form of goto and label statements; therefore links in the Grafcet programs can replace them. Examples are given to help show how to perform these conversions.

Break statement : break;

The break statement is equivalent to a goto statement which passes control to next statement after the smallest enclosing while, do, for, or switch statement. The break statement is shown earlier in the discussion of the switch statement. Examples of the break statement in the while, do, and for statements are shown below. The links in the examples which are added for the break statements are shown as dashed lines.

Examples : while ( expressionl ) \{

statement1;

if ( expression2 ) break;

statement2;

\}

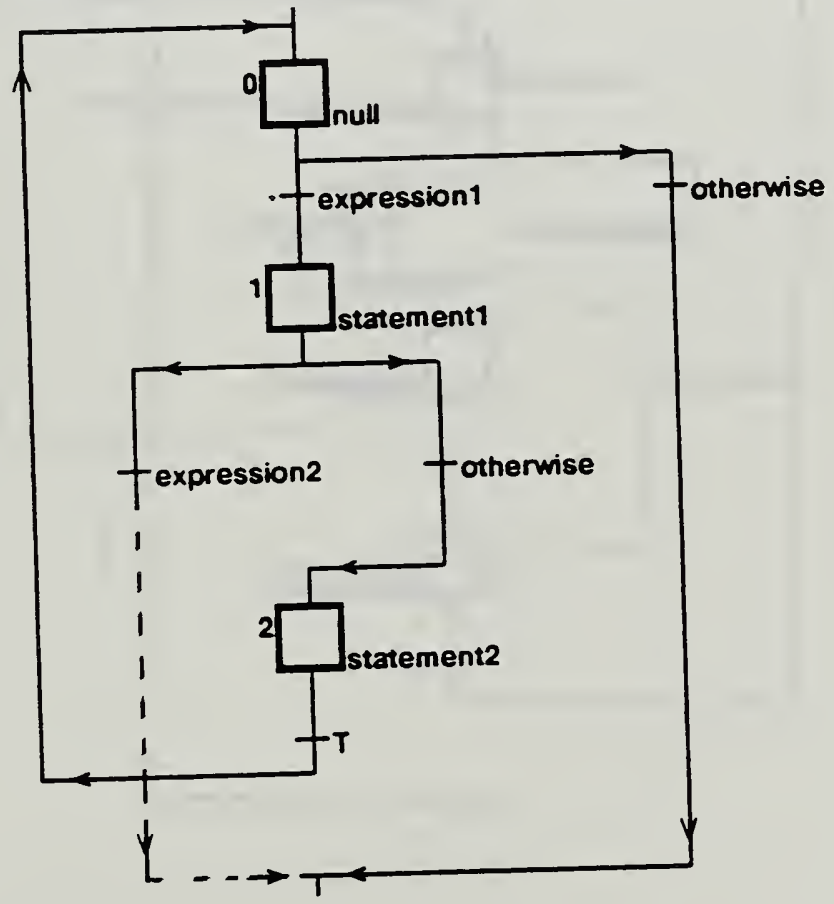

(break in a while statement in Grafcet) 
for ( expression 1 ; expression 2 ; expression 3 ) \{ statement1;

if ( expression4 ) break;

statement2;

\}

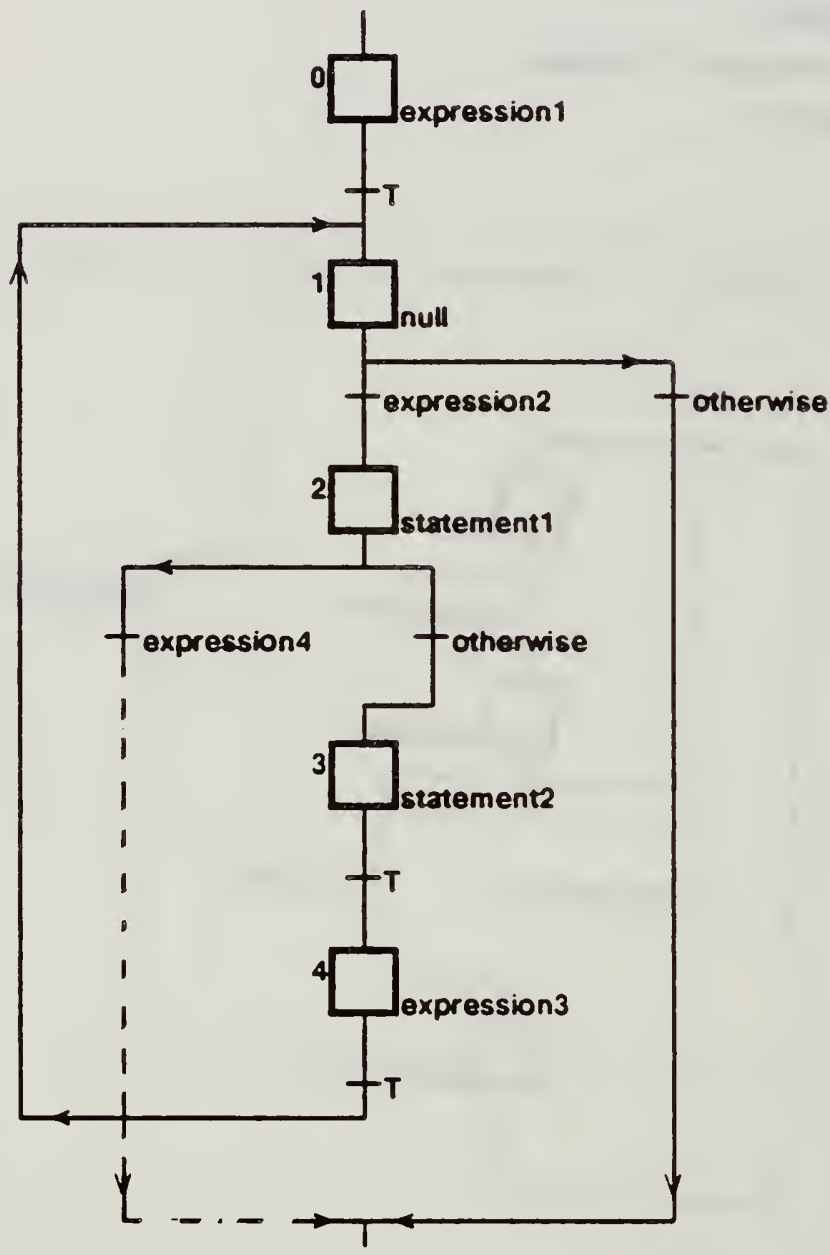

(break in a for statement in Grafcet) 
do \{

statement1;

if ( expression2 ) break;

statement2;

\} while ( expression1 ) ;

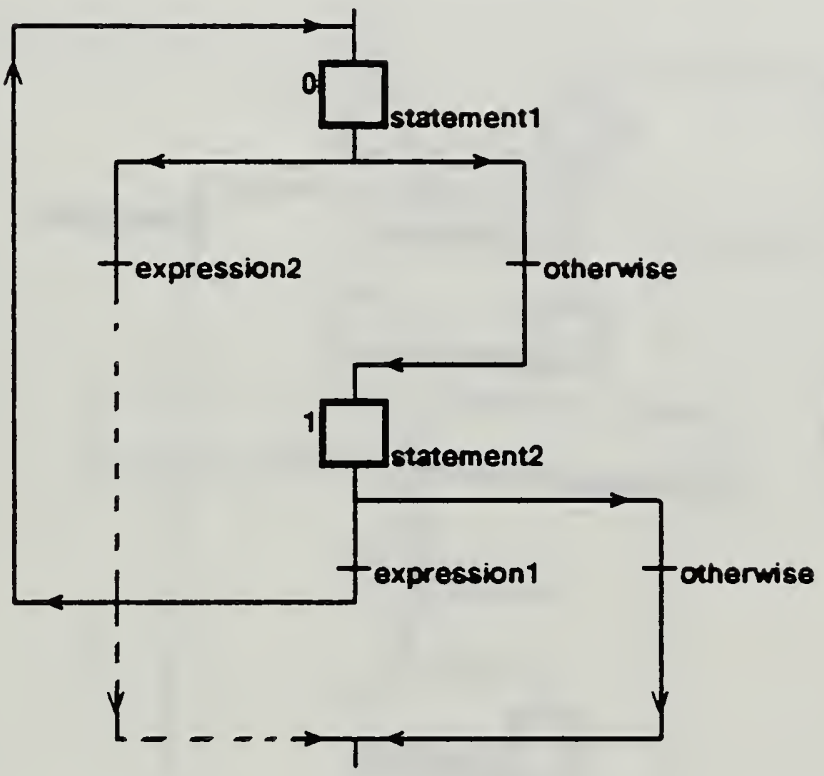

(break in a do statement in Grafcet) 
Continue statement : continue ;

The continue statement causes control to pass to the loop-continuation portion of the smallest enclosing while, do, or for statement. Examples of the continue statement in the while, do, and for statements are shown below. The links in the examples which are added for the continue statements are shown as dashed lines.

Examples : while ( expression1) \{ statement1;

if (expression2) continue;

statement2;

\}

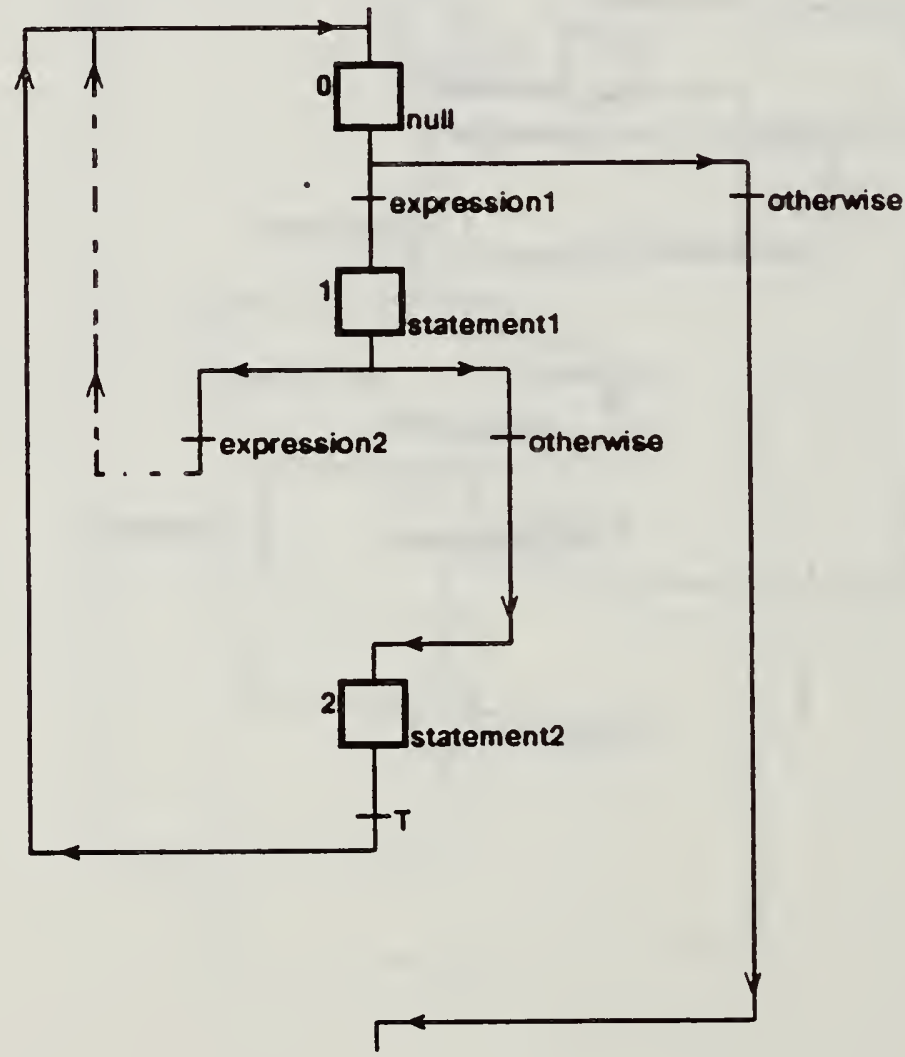

(continue in a while statement in Grafcet) 
for ( expression1 ; expression2 ; expression 3 ) \{

statement1;

if (expression4) continue;

statement2;

\}

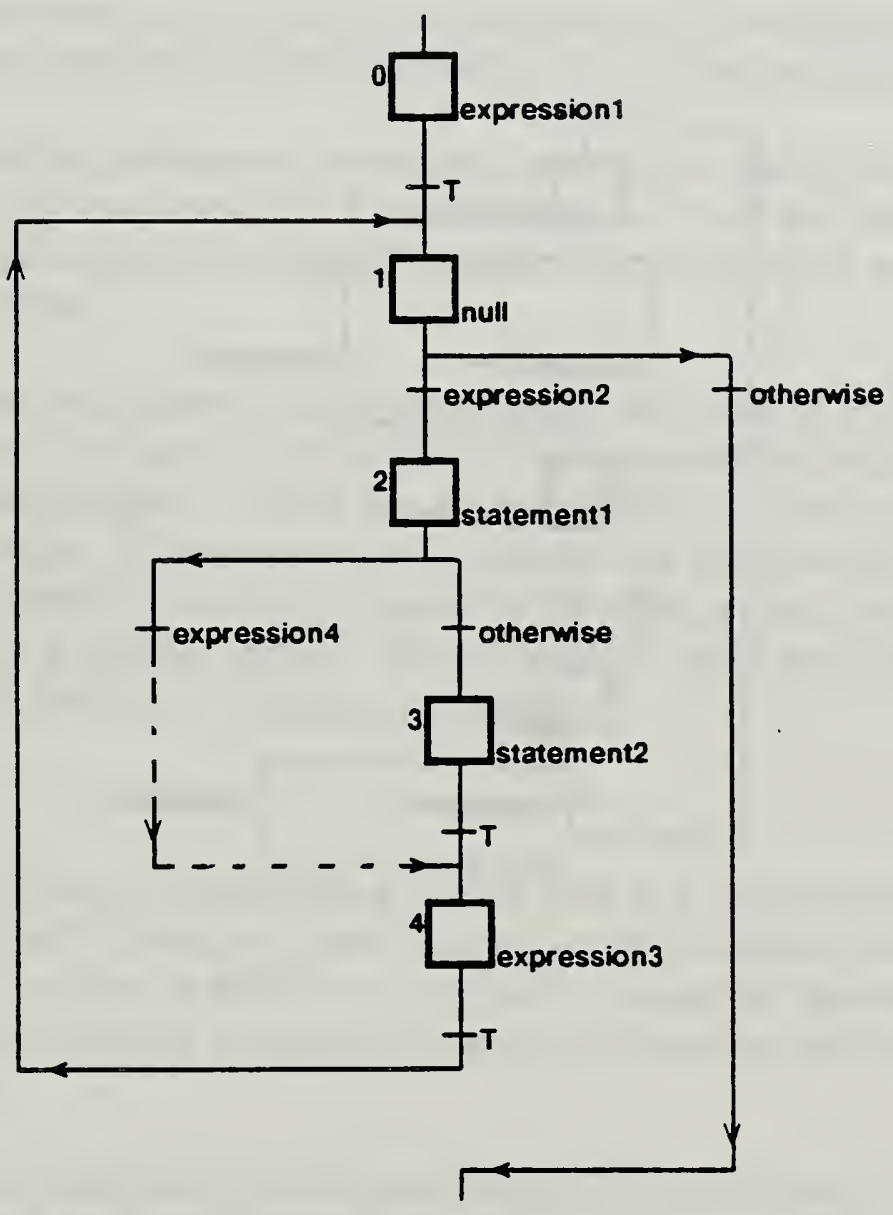

(continue in a for statement in Grafcet) 
do \{

statement1;

if ( expression2) continue;

statement2;

\} while ( expression1);

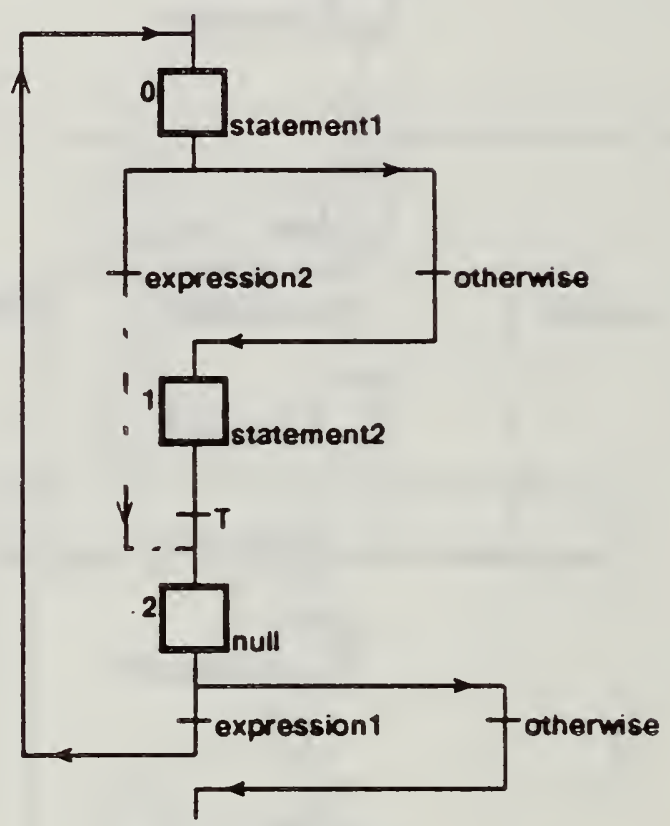

(continue in a do statement in Grafcet) 


\section{Representing Function Calls as Macro Steps :}

This is a discussion of some possible solutions to the problem of translating function calls to Grafcet macro programs, but this is not to be taken as a definitive translation scheme between $\mathrm{C}$ source code and Grafcet for functions. This section contains a description of the problems representing $\mathrm{C}$ function calls in Grafcet, a possible parameter passing scheme in Grafcet, and a possible solution to this limitation that a macro program can be used only once.

There are some problems inherent in the Grafcet language which makes representing function calls difficult. One problem is that macros do not support parameter passing. A second matter is that macros do not have return values. A third matter is that Grafcet programs become cumbersome when they become very large because of their graphical nature. A fourth matter is that return statements have to be included in the Grafcet macro programs that are associated with the enter and exit portion of the function. A final problem is that a Grafcet macro program can only be used once in a Grafcet system.

A possible solution to the problems of parameter passing is to assign the parameters to variables which are only used locally to a macro program. There are scoping rules in Grafcet that allow for making local copies of global variables. A return value would have to be passed as a global variable.

Consider the limitation of a Grafcet macro being called only once in a Grafcet system. If a function is called more than once in a $\mathrm{C}$ program, that function then has to be translated into multiple Grafcet macro programs. There has to be a copy of the Grafcet macro program each time the function is called. There also has to a unique name for each copy of the macro program generated. Another solution is to keep the function in the $\mathrm{C}$ programming language and add the function to a callable library. This in itself can cause problems with timing and mixing control flow in both the $\mathrm{C}$ code and the Grafcet.

\section{Conclusion:}

The paper provides a scheme for translating control flow in $\mathrm{C}$ source code into Grafcet. The control constructs are easily translated from $\mathrm{C}$ source code to Grafcet, but control flow through the use of $\mathrm{C}$ functions is difficult to translate. It might be appropriate to augment Grafcet in some way to allow for parameter passing, return values, and macros which can be called multiple times.

Grafcet is being used for designing and documenting Cell Controllers in the Automated Manufacturing Research Facility (AMRF) at the National Bureau of Standards. A major language used for writing these controllers is $C$ and this translation scheme was used to translate the high level logic of the Cell Controller [6]. Grafcet has provided an excellent means of visualizing the control structure of these large systems.

\section{References:}

[1] Savoir [1986] "Savoir Grafcet" Savoir, Oakland, CA. 
[2] Kernighan, B. W., and Ritchie D. M. [1978] The C Programming Language, PrenticeHall, Inc.

[3] Knuth, D. E. [1974] "Structured Programming with go to Statements", Computer Surveys, 6, 4, 261-277.

[4] Wirth N. [1974] "On the Composition of Well-Structured Programs", Computer Surveys, $6,4,247-259$.

[5] Dijkstra, E. W. [1968] "Go To Statement Considered Harmful", Comm. ACM, 11, 3, 147-148.

[6] Pratt T. W. [1975] Programming Languages: Design and Implementation, Prentice-Hall, Inc.

[7] Thomas B. H., and McLean C. [1988] "Using Grafcet to Design Generic Controllers" First International Conference on Computer Intergrated Manufacturing ( to be presented ). 


\section{Appendix:}

This section shows some examples of translations of $\mathrm{C}$ source code to Grafcet. The function "atoi", converts of an ASCII string to an interger number. In the example, the first section is the $\mathrm{C}$ source code and the second section is the Grafcet programs with associated $\mathrm{C}$ source code embedded in the regular steps.

\section{Example :}

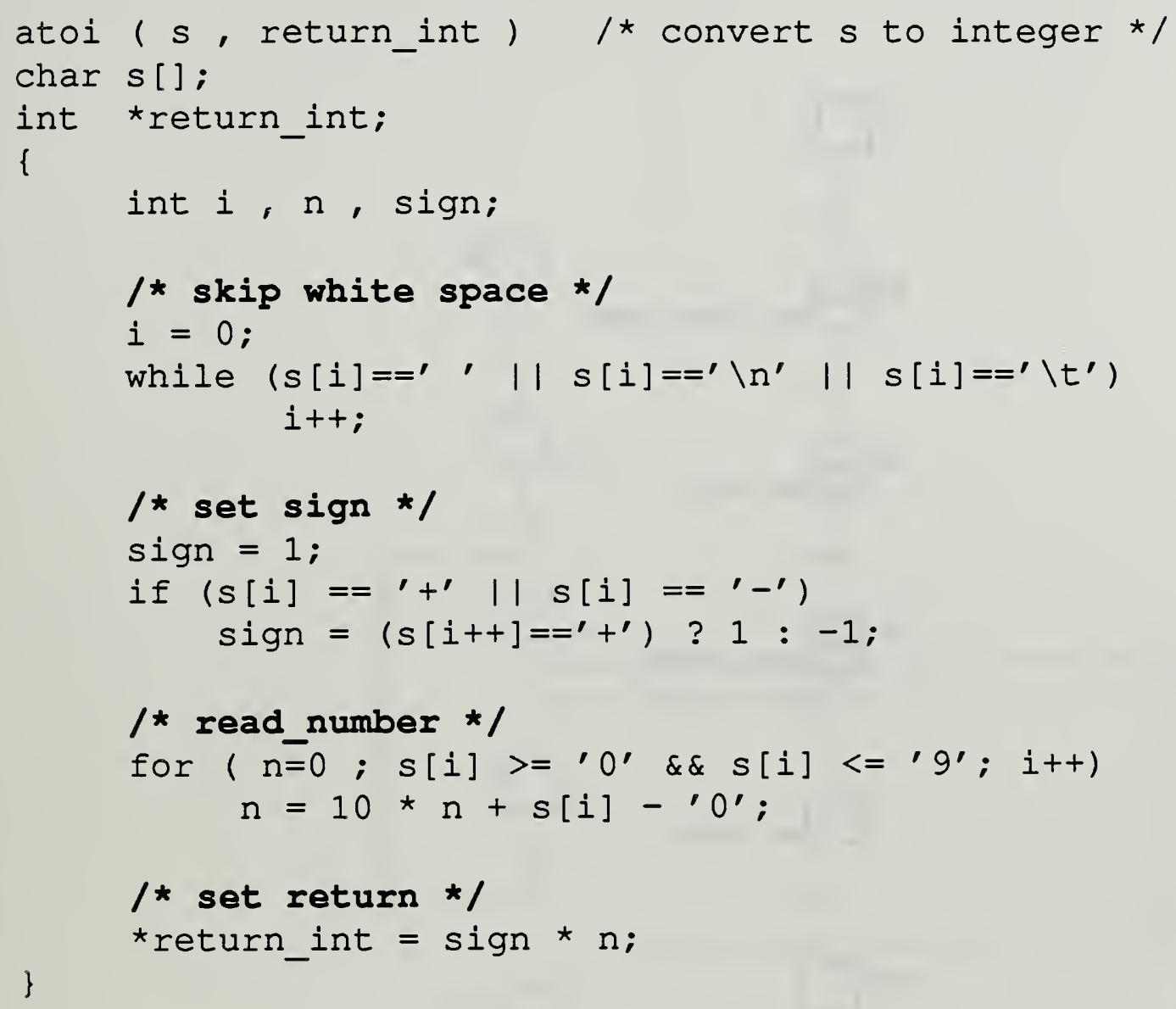




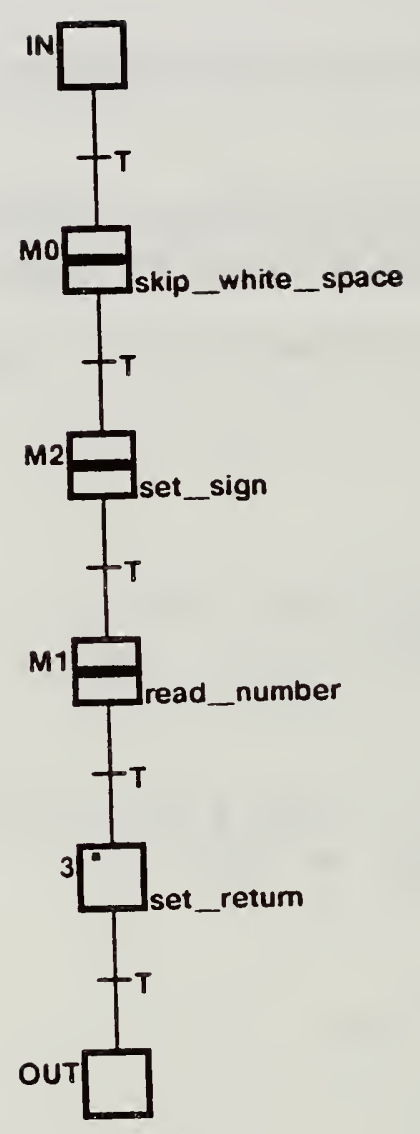

(atoi Grafcet program)

$\sim \mathrm{ii} \sim$ 


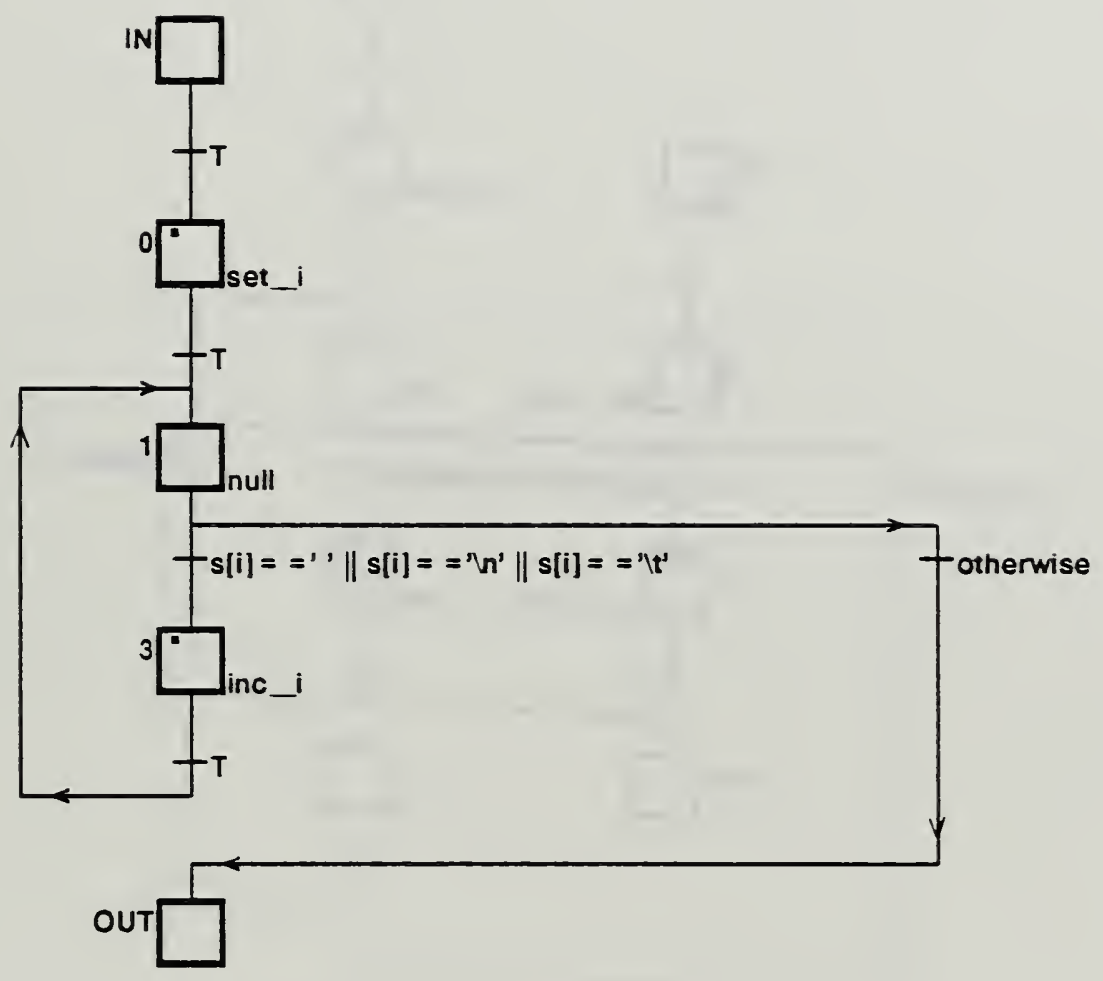

(skip_white_space Grafcet program)

〜iii 


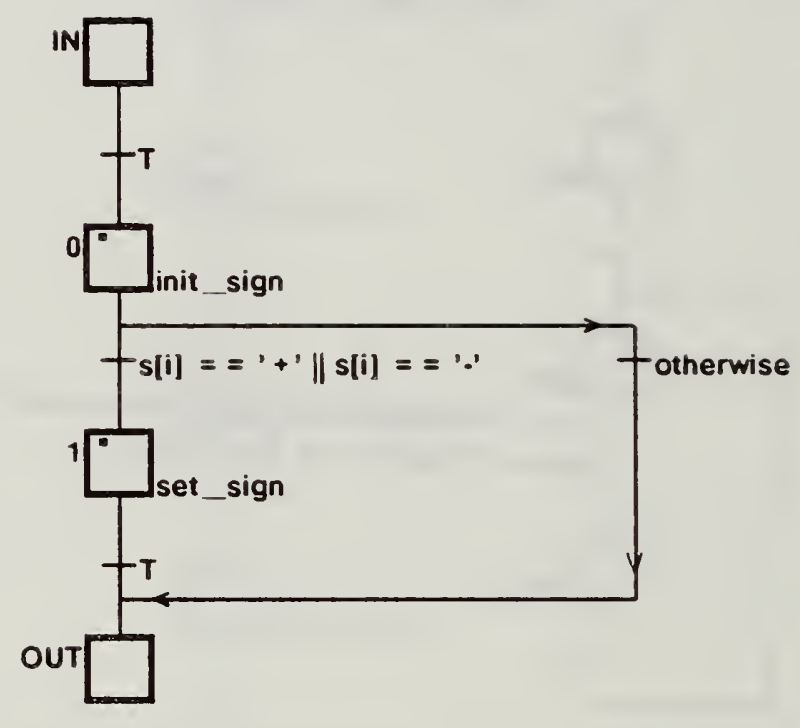

(set_sign Grafcet program)

〜iv 


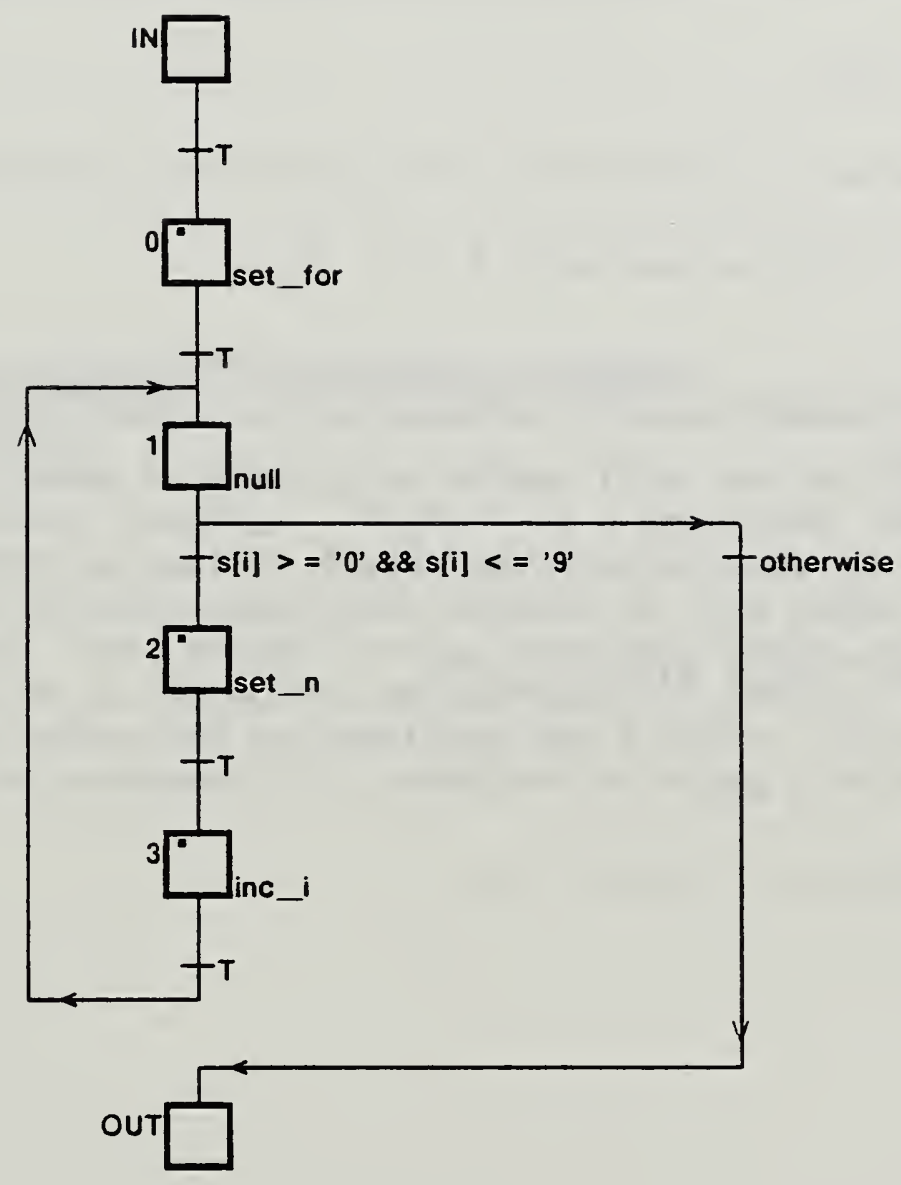

(read_number Grafcet program) 
These blocks of code are associated with labeled regular steps in the Grafcet programs associated with the function atoi.

set_i:

$$
i=0 ;
$$

inc_i:

$$
\text { i++; }
$$

init_sign:

$$
\operatorname{sign}=1
$$

set_sign:

$$
\operatorname{sign}=\left(\operatorname{s}[i++]==^{\prime}+^{\prime}\right) ? 1:-1 ;
$$

set_for:

$$
\mathrm{n}=0 ;
$$

set_n:

$$
\mathrm{n}=10 * \mathrm{n}+\mathrm{s}[\mathrm{i}]-\mathrm{\prime}^{\prime} ;
$$

set_return:

$$
\text { return_int }=\operatorname{sign} * n \text {; }
$$




\begin{tabular}{|c|c|c|c|}
\hline $\begin{array}{l}\text { U.S. DEPT. OF COMM. } \\
\text { BIBLIOGRAPHIC DATA } \\
\text { SHEET (SEe instruCtions) }\end{array}$ & $\begin{array}{l}\text { 1. PUBLICATION OR } \\
\text { REPORTNO. } \\
\text { NBSIR } 8-3.741\end{array}$ & 2. Performing Organ. Report Nod & $\begin{array}{l}\text { 3. Publication Date } \\
\qquad \text { MARCFi } 1988\end{array}$ \\
\hline \multicolumn{4}{|c|}{$\begin{array}{l}\text { A Scheme for Translating Control Flow in the C Programming Language to Grafcet } \\
\text { With Example }\end{array}$} \\
\hline \multicolumn{4}{|l|}{$\begin{array}{l}\text { 5. AUTHOR(S) } \\
\text { Bruce H. Thomas }\end{array}$} \\
\hline \multicolumn{3}{|c|}{$\begin{array}{l}\text { 6. PERFORMING ORGANIZATION (If joint or other thon NBS, see instructlons) } \\
\text { NATIONAL BUREAU OF STANDARDS } \\
\text { DEPARTMENT OF COMMERCE } \\
\text { WASHINGTON, D.C. } 20234\end{array}$} & $\begin{array}{l}\text { 7. Contract Grant No. } \\
\text { 8. Type of Report \& Period Covered }\end{array}$ \\
\hline
\end{tabular}

10. SUPPLEMENTARY NOTES

Document describes a computer program; SF-185, FIPS Software Summary, is attached.

11. ABSTRACT (A 200-word or less foctuol summory of most significont informotion. If document includes o significont bibliogrophy or literoture survey, mention it here)

The purpose of this paper is to show a translation scheme from control flow in the $C$ programing language to the Grafcet language. Grafcet is a graphical language for expressing control flow. Grafcet is used to design parallel systems such as in a manufacturing environment. The control constructs covered in this paper are: conditional statement, while, do, for, switch, break, continue, goto, label, and null. The Grafcet used in this paper is the language, as augmented by Savoir. The $C$ programming language is the one described by Kernighan and Ritchie. This translation is to be used as a reference for programmers to translate existing $C$ source code into Grafcet.

12. KEY WORDS (Six to twelve entries; alphobetical order; copitolize only proper nomes; and seporote key words by semicolons) Grafcet, C programing language, control flow, programing languages

\section{AVAILABILITY}

Unlimited

For Official Distribution. Do Not Release to NTIS

Order From Superintendent of Documents, U.S. Government Printing Office, Washington. D.C. 20402.

Q Order From National Technical Information Service (NTIS). Springfield, VA. 22161

14. NO. OF PRINTED PAGES 29

15. Price

$\$ 11.25$ 


